\title{
O raciocínio matemático nos alunos do Ensino Básico e do Ensino Superior ${ }^{*}$
}

\section{Mathematical reasoning in Elementary School and Higher Education}

\author{
João Pedro da Ponte* \\ Joana Mata-Pereira ${ }^{* * *}$ \\ Ana Henriques ${ }^{* * * *}$
}

\begin{abstract}
Resumo: Este artigo analisa os processos de raciocínio em tarefas matemáticas de dois alunos do $9^{\circ}$ ano do Ensino Básico e dois alunos do $2^{\circ}$ ano do Ensino Superior. Debruçamo-nos, também, sobre a representação e a significação, dada a sua estreita relação com o raciocínio matemático. Os resultados apresentados têm por base dois estudos de natureza qualitativa e interpretativa que usam diversas fontes de dados. Estes resultados mostram que o domínio da linguagem algébrica por parte dos alunos do $9^{\circ}$ ano é ainda insuficiente para resolverem de forma expedita os problemas propostos, o que já não ocorre com os alunos do Ensino Superior. As estratégias iniciais de todos alunos são de natureza indutiva. No entanto, uma das alunas do $9^{\circ}$ ano e os dois alunos do Ensino Superior mostram uma capacidade já bem visível para raciocinar dedutivamente. Os níveis de significação variam consideravelmente, tendo diversos alunos mostrado capacidade de construir ou mobilizar significados relevantes. O modelo de análise que apresentamos, articulando raciocínio, representações e significação, revelou-se um instrumento promissor para estudar os processos de raciocínio dos alunos.
\end{abstract}

Palavras-chave: Raciocínio matemático. Representações. Significação.

\begin{abstract}
This paper analyzes the reasoning processes in mathematical tasks of two students in the $9^{\text {th }}$ year of elementary school and two students in the second year of college. It also focuses the representation and meaningfulness, given their close relation with the mathematical reasoning. Results presented are based on two qualitative and interpretive studies which resort to several data sources. These results show that mastering of the algebraic language by the students in the $9^{\text {th }}$ year is still insufficient to promptly solve the problems proposed, which does not occur with the college students

\footnotetext{
Este trabalho é financiado por fundos nacionais através da Fundação para a Ciência e Tecnologia FCT no âmbito do Projeto "Práticas Profissionais dos Professores de Matemática" (contrato PTDC/ CPE-CED/0989311/2008). Na sua origem está uma comunicação dos dois primeiros autores no Encontro de Investigação em Educação Matemática - EIEM de 2011 e a tese de doutoramento da terceira autora.

** Professor catedrático no Instituto de Educação da Universidade de Lisboa. E-mail: <jpponte@ie.ul.pt>

*** Bolseira do Instituto de Educação da Universidade de Lisboa. E-mail: < joanamatapereira@campus.ul.pt>

**** Professora auxiliar no Instituto de Educação da Universidade de Lisboa. E-mail: <achenriques@ie.ul.pt>
} 
though. All students use inductive initial strategies. However, one of the students in the $9^{\text {th }}$ year and both college students revealed clearly their capability to reason deductively. The signification levels vary considerably, and several students have shown skills to build or mobilize relevant meanings. The model of analysis presented, articulating reasoning, representations and meaningfulness proved itself a promising tool to study the students' reasoning processes.

Keywords: Mathematical reasoning. Representations. Meaningfulness.

\section{Introdução}

O grande objetivo do ensino da Matemática é o desenvolver a capacidade de raciocínio dos alunos. Trata-sede um objetivo ambicioso, mas necessário, que justifica o importante papel da Matemática em todos os sistemas educativos. Os alunos não desenvolvem a capacidade de raciocínio matemático por simples memorização de conceitos, representações e procedimentos rotineiros, que, pelo contrário, os leva a ter uma visão da Matemática como um conjunto de regras mais ou menos desconexas, e não como uma disciplina lógica e coerente (ME, 2007). Para desenvolver esta capacidade é preciso trabalhar em tarefas que, por um lado, requerem raciocínio e, por outro lado, estimulam o raciocínio. Só deste modo se pode esperar uma compreensão efetiva dos conceitos e procedimentos matemáticos por parte do aluno.

A compreensão dos conceitos não se reduz a conhecer a sua definição requer também perceber o modo como estes conceitos se relacionam uns com os outros e como podem ser usados na resolução de problemas. Além disso, a compreensão dos procedimentos passa não só pela sua aplicação, mas também por perceber a razão porque funcionam, como podem ser utilizados e como podem ser interpretados os seus resultados (NCTM, 2009). Deste modo, ser capaz de raciocinar é essencial tanto para usar eficazmente a Matemática em diversas situações, como para a sua própria compreensão (NCTM, 2007). Para progredirmos na compreensão do modo de atingir este objetivo, um passo fundamental é conhecer melhor os processos de raciocínio dos alunos.

Este artigo, então, analisa os processos de raciocínio de alunos do $9^{\circ}$ ano do Ensino Básico e do $2^{\circ}$ ano do Ensino Superior em diversas tarefas, com o objetivo de compreender melhor esses processos, bem como diagnosticar eventuais lacunas no seu desenvolvimento. Pela sua importância especial, centramos a nossa atenção nos tipos de raciocínio indutivo e dedutivo e na justificação, como base do processo do raciocínio matemático. Consideramos igualmente outros processos como a formulação de questões e conjeturas e o respetivo teste e debruçamo-nos, também, sobre a representação e a significação, dada a sua estreita relação com o raciocínio. 


\section{Raciocínio matemático}

O raciocínio matemático é reconhecido como fundamental por numerosos autores, que sublinham uma variedade de aspetos. Por exemplo, Oliveira (2008, p. 3) usa a expressão raciocinio matemático para referir "um conjunto de processos mentais complexos através dos quais se obtêm novas proposições (conhecimento novo) a partir de proposições conhecidas ou assumidas (conhecimento prévio)". Numa perspectiva lógica, Aliseda (2003) identifica raciocínio matemático com inferência dedutiva, caracterizada pela certeza e pela monotonicidade, ou seja, pela existência de uma relação necessária entre premissas e conclusão e pela irrefutabilidade das conclusões. Numa perspectiva mais abrangente, Russel (1999, p. 1) refere que, na aprendizagem da Matemática, o raciocínio é "o que usamos para pensar sobre as propriedades de um determinado objeto matemático e desenvolver generalizações que se apliquem a toda a classe de objetos" e é "a ferramenta para compreender a abstração". Deste modo, enquanto alguns autores salientam sobretudo os aspetos lógicos, outros valorizam mais os processos intuitivos, como se formulam novas ideias e se chegam a novas conclusões.

\section{Raciocínio indutivo e dedutivo}

Em Portugal, o raciocínio matemático surge como capacidade transversal no Programa de Matemática oficial (ME, 2007). Oliveira (2002), ao estudar o raciocínio do ponto de vista epistemológico, identifica quatro grandes tipos: (i) indução; (ii) dedução; (iii) abdução; e (iv) transformação. A discussão de semelhanças e diferenças entre os raciocínios indutivo e dedutivo constitui um ponto de partida para a análise do que caracteriza o raciocínio matemático e os seus processos.

Segundo Pólya (1954), a indução inicia-se muitas vezes através da observação, a partir da qual se desenvolvem conjeturas a testar posteriormente. Este autor refere ainda outros processos importantes no raciocínio indutivo e que ocorrem frequentemente durante a resolução de problemas matemáticos, nomeadamente a generalização, a especialização e a analogia. Oliveira (2002, p. 174) sublinha igualmente a estreita relação entre analogia e indução salientando que "quem induz fá-lo por analogia, i.e., a pessoa infere a semelhança das conclusões a partir da diferença dos factos". Por outro lado, é através do raciocínio indutivo que se elaboram conjeturas que podem ser posteriormente verificadas. Neste sentido, o raciocínio indutivo é heurístico, desenvolvendo-se do particular para o geral, sem conduzir a conclusões necessárias, mas com um papel chave na criação de novo conhecimento (OLIVEIRA, 2002).

Por outro lado, o raciocínio dedutivo é característico da Matemática, na qual ocupa um lugar fundamental. É um raciocínio formal, relacionado com as 
demonstrações e a lógica. Demonstrar envolve sobretudo encadear asserções de forma lógica e justificar esse encadeamento. Como indica Oliveira (2008, p. 7), desde que a cadeia de deduções esteja isenta de erros, "o raciocínio dedutivo produz conclusões que são necessariamente válidas". O raciocínio dedutivo constitui "o elemento estruturante, por excelência, do conhecimento matemático" (OLIVEIRA, 2002, p. 178), sendo um raciocínio lógico, desenvolvido do geral para o particular, com conclusões necessárias e com um papel essencial na validação de conhecimento.

\section{Processos de raciocínio}

Os processos de raciocínio incluem a formulação de questões, a formulação e teste de conjeturas e a realização de justificações. Tanto as questões como as conjeturas podem ser mais específicas ou mais gerais. Um importante processo de raciocínio é a generalização, que parte de uma conclusão ou conjetura específica para formular uma conjetura de âmbito mais geral.

No $3^{\circ}$ ciclo do Ensino Básico espera-se que a justificação se apoie em procedimentos, propriedades e definições matemáticas, fundamentando as afirmações em todas as atividades realizadas (ME, 2007). É também expectável que os alunos sejam capazes de distinguir uma argumentação informal de uma argumentação formal. Ainda que sem alcançar o rigor associado à demonstração matemática, as justificações devem apresentar algumas das suas características, sendo mais formais do que em ciclos anteriores. A explicação e justificação de conclusões permitem aos alunos esclarecer o seu raciocínio (NCTM, 2007). No Ensino Superior, espera-se que tais capacidades estejam mais amadurecidas e que os alunos, em especial nos cursos onde a Matemática assume um papel de relevo, estejam preparados para realizar demonstrações e compreender a sua importância.

O incentivo à justificação desde os primeiros anos promove a progressão entre as justificações simples e informais e as justificações formais. A formalização e encadeamento de justificações conduzem naturalmente à realização de demonstrações. Contudo, não se espera que os processos de demonstração sejam desenvolvidos desde os primeiros anos de escolaridade de um modo rigorosamente formal. No $3^{\circ}$ ciclo do Ensino Básico, os alunos devem ser capazes de: (i) formular, testar e justificar conjeturas; (ii) distinguir entre uma demonstração e um teste de uma conjetura; (iii) fazer demonstrações simples; (iv) identificar e usar raciocínio indutivo e dedutivo; (v) compreender o papel das definições em Matemática; (vi) distinguir uma justificação informal e uma demonstração; e (vii) selecionar e usar vários tipos de raciocínio e métodos de demonstração (ME, 2007). 
Para que os alunos se tornem competentes na utilização do raciocínio indutivo e dedutivo, é necessário que haja espaço para a discussão de conjeturas e afirmações matemáticas com o professor e os colegas (NCTM, 2007). Neste nível de ensino, espera-se que os alunos estejam familiarizados com processos de raciocínio, como a formulação de uma conjetura, o teste desta conjetura e a apresentação do raciocínio utilizado, ainda que sem o formalismo associado à demonstração matemática (NCTM, 2007).

Os problemas e as tarefas de investigação constituem um contexto fundamental para o estudo do raciocínio matemático, atendendo aos processos usualmente usados na elaboração e teste de conjeturas e na sua justificação (PONTE; BROCARDO; OLIVEIRA, 2003). Um quadro conceptual para a análise do raciocínio que relaciona estas ideias encontra-se na Figura 1. O raciocínio indutivo tem lugar sobretudo na formulação de conjeturas gerais a partir de casos específicos, e o raciocínio dedutivo ocorre principalmente nos processos de justificação. Note-se que o raciocínio apoia-se nas representações e articula-se com os processos de significação (sense making) que consistem em desenvolver a compreensão de uma situação, contexto ou conceito conectando-o com conhecimento existente (NCTM, 2009). Por isso discutimos em seguida, embora de modo breve, estes conceitos.

Figura 1 - Quadro conceptual para a análise do raciocínio

\section{Significar}

("Sense making")

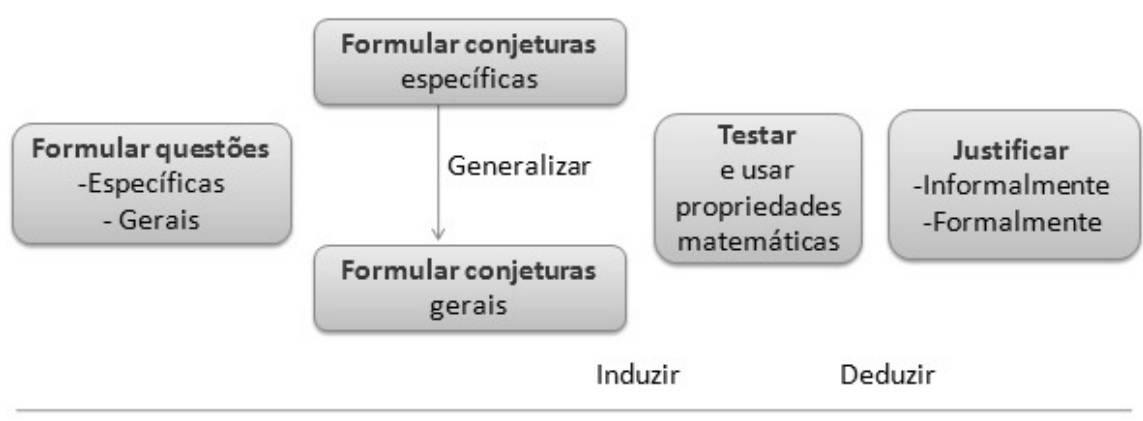

\section{Representar}

Linguagem natural, pictórica, algébrica, geométrica, estatística...

Fonte: Adaptado de Mata-Pereira e Ponte (2011).

\section{Representações}

Aceder diretamente ao raciocínio matemático dos alunos é, naturalmente, impossível. Para conhecer minimamente este raciocínio é necessário que os 
alunos o comuniquem, o que só é possível através de diferentes representações. Deste modo, como refere o NCTM (2007, p. 76), somente "ao observar as suas representações (dos alunos), os professores poderão conseguir compreender os modos de interpretação e de raciocínio dos alunos". Contudo, para além do papel que assumem na comunicação de raciocínios, as representações assumem também um papel decisivo na aprendizagem. Como salienta o NCTM (2007, p. 75), "quando os alunos conseguem aceder às representações matemáticas e às ideias que elas expressam, ficam com um conjunto de ferramentas que aumentam significativamente a sua capacidade de pensar matematicamente". Em Portugal, um dos objetivos gerais do programa de Matemática do Ensino Básico foca também a necessidade de os alunos compreenderem e saberem usar diferentes tipos de representações (ME, 2007). Este programa destaca igualmente que "as representações matemáticas desempenham um papel importante em toda a aprendizagem desta disciplina, e o trabalho com os conceitos matemáticos mais importantes deve envolver, sempre que possível, mais do que uma forma de representação" (ME, 2007, p. 9).

Outros autores defendem também a necessidade do estudo das representações. Por exemplo, Vergnaud (1998, p. 167) apresenta duas razões distintas: (i) "todos experimentamos representações como um conjunto de imagens internas, gestos e palavras" e (ii) "as palavras e símbolos que usamos para comunicar não se referem diretamente à realidade, mas a representações de objetos, propriedades, relações, processos, ações e construções sobre as quais não existe um acordo automático entre duas pessoas". Pelo seu lado, Duval (2004, p. 25) defende ainda que "não é possível estudar os fenómenos relativos ao conhecimento sem recorrer à noção de representação [...] pois não há conhecimento que um sujeito possa mobilizar sem uma atividade de representação". Similarmente, Goldin (2008) apresenta os construtos de representação, sistemas de representação e desenvolvimento de estruturas de representação como componentes essenciais para a aprendizagem da Matemática. Por outro lado, Greeno e Hall (1997, p. 361) sublinham a relevância das representações na sua relação com o raciocínio ao referirem que "aprender a construir e interpretar representações envolve aprender a participar nas práticas complexas de comunicar e raciocinar, nas quais as representações são utilizadas".

As representações constituem, então, um elemento central no ensinoaprendizagem da Matemática e, consequentemente, no desenvolvimento e compreensão dos processos de raciocínio matemático dos alunos. No entanto, o conceito de representação é um conceito complexo que pode ser encarado de diversas formas. Assim, segundo Goldin (2008, p. 181) uma representação é uma configuração que poderá, de alguma forma, "atuar no lugar de, ser interpretado como, corresponder a, denotar, descrever, encarnar, codificar, invocar, categori- 
zar, ligar com, mediar, produzir, referir a, assemelhar, servir como metáfora para, significar, substituir por, sugerir ou simbolizar o que está a ser representado". Pelo seu lado, Duval (2006) salienta ainda que os objetos matemáticos nunca devem ser confundidos com a sua representação e refere que este é um dos problemas cruciais da compreensão matemática, na medida em que não é possível aceder a um objeto matemático sem as representações, o que torna ambígua a distinção entre o objeto representado e a representação usada. Duval (2004, p. 30) caracteriza também registros semióticos de representação como constituindo "a margem de liberdade de um sujeito para objetivar ele mesmo uma ideia ainda confusa, um sentimento latente, para explorar as informações ou, simplesmente, para as comunicar a um interlocutor".

Duval (2004) encara as representações semióticas como representações externas, e as representações mentais como internas. Também Goldin (2008) distingue representações externas e internas, sendo estas últimas as relacionadas com os sistemas de representações psicológicas dos indivíduos que não podem, em circunstâncias habituais, ser observadas por terceiros. Organiza as representações internas em cinco tipos de sistemas inter-relacionados: (i) verbal e semântico; (ii) imagético; (iii) notação formal; (iv) planeamento, monitorização e controlo de execução; (v) afetivo. Cada um destes sistemas permite ao indivíduo produzir um vasto leque de representações externas complexas e específicas que podem ser interpretadas por terceiros: (i) linguagem oral e escrita; (ii) gestos icónicos, desenhos, representações pictóricas, produções musicais ou rítmicas; (iii) fórmulas matemáticas e equações; (iv) expressões de objetivos, intenções, planeamento, estruturas de decisão; e (v) contacto visual, expressões faciais, linguagem corporal, contacto físico, lágrimas, gargalhadas e exclamações que transmitem emoções.

Duval (2004, 2006) apresenta duas transformações de representações semióticas que considera profundamente distintas: tratamentos e conversões. Tratamentos são transformações de representação que ocorrem dentro de um mesmo registro e que revelam o papel intrínseco dos registros semióticos de representação na atividade matemática. São exemplos de tratamentos resolver equações ou sistemas de equações, realizar um cálculo sem sair de um dado sistema de notação ou ainda completar uma figura utilizando critérios de conectividade ou simetria. Por outro lado, conversões são transformações de representação que consistem em transformar a representação de um objeto, de uma situação ou de uma informação de um dado registro semiótico numa outra representação do mesmo objeto, situação ou informação de um outro registro semiótico. As conversões consistem, assim, em mudanças de registro semiótico de representação. São exemplos de conversões a passagem de uma equação algébrica para a sua representação gráfica ou a passagem de uma constatação sobre uma relação em linguagem natural para a sua notação utilizando letras. 
A passagem de um registro para outro nem sempre é simples, mas é muitas vezes necessária para uma adequada compreensão do objeto em questão. O NCTM (2007, p. 77) refere esta ideia ao indicar que "representações distintas focam, geralmente, aspetos diferentes de relações e conceitos complexos" pelo que, para se tornarem conhecedores de conceitos matemáticos, "os alunos necessitam de uma diversidade de representações que suportem a sua compreensão". Complementarmente, segundo Duval (2004), do ponto de vista cognitivo, as aprendizagens fundamentais relativas ao raciocínio requerem a diversificação dos registros semióticos de representação, a diferenciação entre representante e representado e ainda a coordenação entre os diferentes registros.

\section{Significação}

O desenvolvimento do raciocínio matemático e a compreensão da Matemática passam também pelo estabelecimento de conexões, através do qual os alunos desenvolvem a sua capacidade de pensar matematicamente e, consequentemente, de raciocinar matematicamente. As conexões surgem como uma característica fundamental da atividade matemática, como "um elemento estruturante do fazer matemática e do pensar matematicamente" (CARREIRA, 2010, p. 18). O programa de Matemática do Ensino Básico salienta que "o estabelecimento de conexões é essencial para uma aprendizagem da Matemática com compreensão e para o desenvolvimento da capacidade de a utilizar e apreciar" (ME, 2007, p. 6). O NCTM (2007, p. 71) realça ainda que "quando os alunos conseguem estabelecer conexões entre ideias matemáticas, a sua compreensão é mais profunda e duradoura". As conexões assumem assim um destaque significativo no ensino e na aprendizagem da Matemática.

De acordo com Ponte e Sousa (2010), o uso do termo conexões é recente tanto nos documentos curriculares como no discurso profissional, pelo que a sua discussão, tendo por referência o ensino da Matemática, é de especial importância. Um dos significados de conexão que melhor se coaduna com a perspectiva de conexões em Matemática é o de relação, nexo, analogia ou afinidade entre coisas diversas (Dicionário da Língua Portuguesa Contemporânea - Academia das Ciências de Lisboa). Muitos educadores matemáticos têm focado a sua atenção nas conexões com a vida real ou na contextualização para que os alunos criem significados para os conceitos. Contudo, os problemas "reais" e as contextualizações deixam muitas das grandes áreas da Matemática injustificadas (HOWSON, 2005). Segundo Boavida et al. (2008), as conexões em Matemática referem-se não só às situações em que os alunos trabalham a Matemática ligada a problemas da vida real e a outras áreas curriculares, como também à relação entre tópicos ou temas matemáticos diferentes, ou seja, as conexões com a realidade e com outras áreas do saber e as conexões dentro da Matemática. É ainda importante 
salientar que as conexões matemáticas devem ser destacadas e valorizadas não tanto enquanto elementos do conhecimento matemático a adquirir, mas essencialmente enquanto prática matemática de sala de aula (CARREIRA, 2010). Para que tal seja possível, é necessário promover contextos que habilitem os alunos a (i) reconhecer e usar conexões entre ideias matemáticas, (ii) compreender a forma como as ideias matemáticas se inter-relacionam e se constroem umas a partir das outras para produzir um todo coerente e (iii) reconhecer e aplicar a Matemática em contextos que lhe são exteriores (NCTM, 2007). Na sua essência, a ênfase nas conexões matemáticas procura contrariar a visão da Matemática enquanto conjunto de conceitos e capacidades desconectados e isolados e impedir que esta visão degenere em resultados indesejáveis como a compartimentação, a fragmentação, o isolamento, a mecanização e a incompreensão (CARREIRA, 2010).

Estritamente relacionado com as conexões encontra-se o conceito de significação (sense making). Segundo o NCTM, a significação consiste em desenvolver a compreensão de uma situação, contexto, ou conceito conectando-o com conhecimento existente (NCTM, 2009). Neste sentido, a significação apenas é possível ao estabelecer conexões. O documento Focus in High School Mathematics: Reasoning and Sense Making (NCTM, 2009) assume a significação como um aspeto do raciocínio e também o raciocínio como aspeto da significação. Por um lado, o raciocínio formal poderá basear-se em significação que identifica elementos comuns através de determinadas observações e que percebe como esses elementos comuns estabelecem conexões com situações anteriores (NCTM, 2009). Por outro lado, o raciocínio dedutivo ajuda a compreender o significado do que está a ser demonstrado, ou seja, a ver não só o que é verdade mas também porque é verdade (HANNA, 2000). Nesta situação é a significação que se baseia em raciocínio. Esta relação permite compreender que raciocínio e significação se encontram entrelaçados ao longo do processo contínuo entre as observações informais e as deduções formais (Figura 2) (NCTM, 2009).

Figura 2 - Relação entre raciocínio e significação

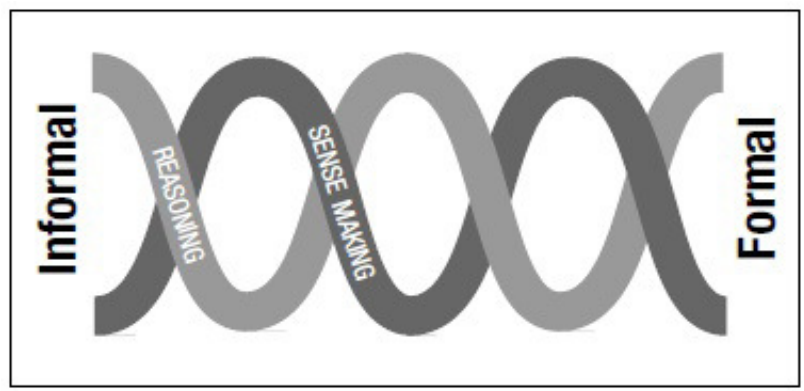

Fonte: NCTM (2009, p. 4). 
Reestruturar o ensino e a aprendizagem da Matemática enquadrando o raciocínio e a significação na prática diária de sala de aula aumenta o desenvolvimento das competências matemáticas dos alunos tanto no que respeita aos conhecimentos como aos processos (NCTM, 2009). Esta reestruturação não implica um "encargo adicional para os professores que se debatem com os alunos que têm dificuldades apenas a aprender os procedimentos" (NCTM, 2009, p. 5). Pelo contrário, a estrutura proporcionada pelo raciocínio e pela significação permite uma aprendizagem continuada da Matemática com compreensão.

No seu conjunto, raciocínio, representações e significação devem ser desenvolvidos no ensino e aprendizagem da Matemática para que os alunos a possam compreender de forma a conseguirem ser bem sucedidos não só na continuidade do seu percurso escolar como também enquanto cidadãos.

\section{Metodologia}

Os resultados apresentados neste artigo têm por base dois estudos de natureza qualitativa, que se inserem no paradigma interpretativo (BOGDAN; BIKLEN, 1994) e recorrem a estudos de caso (STAKE, 2009). Apresentamos primeiro dados relativos a dois alunos, Maria e Duarte, do $9^{\circ}$ ano de escolaridade, inseridos numa turma que trabalha o programa de Matemática anterior (ME, 1992), cuja professora, com cerca de cinco anos de experiência, não teve ainda qualquer envolvimento profissional com o atual programa (ME, 2007). Os alunos foram selecionados apenas segundo o seu desempenho escolar em Matemática, sendo os dois alunos com melhor desempenho da turma. Note-se, porém, que se trata de uma turma com desempenho pouco satisfatório.

Apresentamos em seguida dados relativos a dois alunos universitários, Gonçalo e Luís, recolhidos a partir da realização de tarefas de investigação na disciplina de Análise Numérica, do $2^{\circ}$ ano dos cursos ministrados na Escola Naval. Durante o $1^{\circ}$ ano, estes alunos frequentaram diversas disciplinas de Matemática (Análise Matemática I e II e Álgebra Linear) que utilizam o método tradicional de ensino, com aulas de exposição de teoremas e demonstrações com um grau de formalismo médio ou reduzido, seguidas de outras aulas de resolução de exercícios. Os alunos foram selecionados com base no seu desempenho escolar nas disciplinas de Matemática e num questionário inicial, sendo Gonçalo um aluno de topo do curso de Engenharia Mecânica e Luís um aluno abaixo da média do curso de Administração Naval.

Para a recolha de dados foram utilizados diversos instrumentos, selecionados entre as técnicas mais usadas na metodologia qualitativa: entrevistas individuais ou a pares (E) (videogravadas no $1^{\circ}$ estudo e audiogravadas no $2^{\circ}$ ), análise documental dos relatórios escritos (R) e, no $2^{\circ}$ estudo, observação participante, 
tendo a professora assumido também o papel de investigadora. Atendendo ao objetivo do estudo, a análise dos dados recolhidos é realizada de acordo com as seguintes categorias: (i) representações; (ii) processos de raciocínio, incluindo formulação de questões, justificação e demonstração; e (iii) significação. Em representações pretende-se essencialmente identificar os tipos de transformações usadas, procurando analisar tratamentos e conversões. Em processos de raciocínio, damos atenção à formulação de conjeturas, ao seu teste e verificação, bem como à justificação utilizada. Finalmente, a significação pretende analisar a incidência deste aspeto durante a realização de cada tarefa por parte dos alunos.

\section{Processos de raciocínio em alunos do $9^{\circ}$ ano}

A tarefa seguinte foi proposta aos dois alunos do $9^{\circ}$ ano, Maria e Duarte:

Considera um número natural. Determina a sua soma com os dois números naturais consecutivos seguintes. O que observas? Consegues provar o que afirmas?

Esta tarefa tem a mesma estrutura que as usadas por Arzarello; Bazzini e Chiapinni (2002) para analisar o pensamento algébrico de alunos. Trata-se de um problema que pode ser resolvido através de procedimentos algébricos. $\mathrm{Na}$ sua realização é expectável que os alunos conjeturem sobre as características da soma de quaisquer três números naturais consecutivos e que testem e verifiquem a sua conjetura. Para resolvê-la, é necessário saber representar naturais consecutivos e simplificar expressões algébricas. É também necessário que os alunos tenham presente a noção de múltiplo de um número e o modo de o representar. Anteriormente, os alunos já tinham resolvido tarefas onde se usou a propriedade de $k n+k$ ser um múltiplo de k, para k e $n$ naturais.

Resolução de Maria

A aluna começa por escrever o seguinte:

$$
2+3+4=9
$$

Contudo, não conseguindo observar nada com este exemplo, tenta passar para uma expressão algébrica que represente a situação pretendida. No entanto, demora algum tempo a escrever uma expressão algébrica para a soma de números consecutivos, o que só consegue com dificuldade e após alguma ajuda:

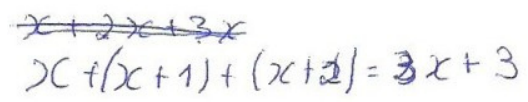


Após escrever e simplificar a expressão algébrica, chega rapidamente a uma conclusão:

Entrevistadora: Então e agora o que é que observas?

Maria: Que vai ser um número... Pois... Então... Se tiver um número e multiplicar por trề vai dar um múltiplo de três, mais três vai dar outro múltiplo de três.

E.: Então se eu somar três números consecutivos o que é que vai acontecer?

M.: Vai ser um múltiplo de três.

Resolução de Duarte

O aluno utiliza uma outra estratégia de resolução da mesma tarefa, apresentando logo de início três casos particulares:

$$
\begin{aligned}
& 2+3+4=9 \\
& 1+2+3=6 \\
& 4+5+6=15
\end{aligned}
$$

Duarte: Dá sempre múltiplos de três!

Entrevistadora: E podes-me provar isso?

D.: [escreve $51+52+53=156]$

E.: E agora vamos descobrir se este é um múltiplo de três? É um múltiplo de três, eu posso-te dizer que esse é. E se en te disser que esse é, tu acreditas que todos são?

D.: Provavelmente.

E.: Provavelmente. E consegues provar que todos são?

D.: Não.

É notório que, apesar do início da resolução remeter para uma estratégia que permitiria dar resposta ao problema, Duarte não consegue concluir essa estratégia.

Após ser proposto a Duarte que tente utilizar linguagem algébrica para realizar a sua prova, observa-se que ele chega com mais facilidade do que Maria a uma expressão que representa a situação e procede à sua simplificação:

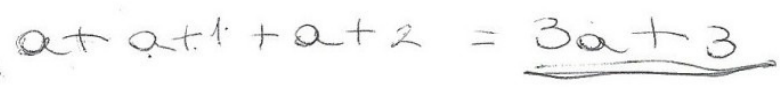

Contudo, para assumir a conclusão como verdadeira, Duarte volta a sentir necessidade de particularizar, tentando validar a sua conclusão usando um caso particular: 


\section{E.: E agora, podes-me dizer que é um múltiplo de três?}

D.: Sim.

E.: Porquê?

D.: Porque... Se for dois [apontando para a] dois vezeses três dá seis mais três dá nove, está certo.

\section{Representações}

Nesta tarefa, Maria tem uma dificuldade clara na conversão da linguagem natural para a algébrica. Esta dificuldade leva a supor que a aluna tem ainda uma compreensão pouco consistente da linguagem algébrica. Contudo, efetua os tratamentos associados às representações externas de fórmulas matemáticas com facilidade, sendo disso exemplo a simplificação da expressão algébrica.

Pelo seu lado, na resolução da tarefa, Duarte usa maioritariamente tratamentos dentro do mesmo sistema de representação. No entanto, quando confrontado com essa necessidade, não mostra qualquer dificuldade na conversão da linguagem natural para a algébrica. Por outro lado, na conversão da linguagem algébrica para a natural, mostra mais dificuldade do que a colega que, possivelmente, tem o conceito de múltiplo mais presente ou melhor compreendido.

\section{Processos de raciocínio}

Maria parece utilizar um processo de raciocínio próximo da dedução. Apesar de ter iniciado a sua estratégia de resolução com um caso particular, rapidamente o abandona. Adota uma nova estratégia utilizando um caso geral, chegando a uma conclusão válida. Pelo seu lado, Duarte inicia a tarefa usando casos particulares. Apesar de não conseguir concluir a sua estratégia, percebe-se que ela tem um caráter eminentemente indutivo.

Ainda que por processos diferentes, ambos os alunos conjeturam que a soma de três números consecutivos é um múltiplo de três (conjetura geral). Maria, após abandonar a primeira estratégia, formula com alguma facilidade uma conjetura que justifica por meio da expressão algébrica simplificada que encontra. Quanto a Duarte, que por si se cinge à conjetura, após a generalização realizada por sugestão da entrevistadora, sente a necessidade de testar essa generalização para justificar que efetivamente representa um múltiplo de três. Este teste não é um teste da sua conjetura inicial, mas um teste de uma generalização que o aluno tem dificuldade em validar sem particularizar.

Significação

Esta tarefa permite aos alunos a exploração de algumas potencialidades da linguagem algébrica na descoberta de propriedades dos números. Maria, ao 
associar a expressão simplificada ao conceito de múltiplo, mostra uma compreensão da simplificação que realiza, relacionando-a com o conceito de múltiplo e evidenciando compreender o que está a ser demonstrado. Por outro lado, Duarte, apesar de conseguir realizar os procedimentos pretendidos, não dá significado à expressão algébrica que obtém. $\mathrm{O}$ aluno não estabelece qualquer relação entre a expressão algébrica simplificada e o conceito de múltiplo já explorado em tarefas anteriores e mostra dificuldade em relacionar a expressão algébrica com as expressões numéricas que usa para formular a conjetura inicial. Durante a resolução da tarefa, as dificuldades do aluno na identificação de elementos comuns nas expressões numéricas e algébricas parecem originar dificuldades no seu raciocínio formal e consequente demonstração da conjetura inicial.

\section{Processos de raciocínio em alunos do Ensino Superior}

Q1. Observe as seguintes situações

$$
[1,2]+[5,7]=[6,9] \quad[0,1]+[-5,2]=[-5,3] \quad[-3,-1]+[1,3]=[-2,2]
$$

Será possível deduzir uma regra que permita determinar a soma de dois intervalos de valores reais? Investigue se todos os intervalos de valores reais seguem esta regra. Investigue se a regra deduzida poderá ser utilizada para outras operações com intervalos, por exemplo, a subtração $(\mathrm{X}-\mathrm{Y})$, a multiplicação $(\mathrm{X} \times \mathrm{Y})$ e a divisão $(\mathrm{X} / \mathrm{Y})$. Em caso negativo, deduza novas regras para essas operações.

Q2. Considere a função $f: D \subset I R \rightarrow I R$, real de variável real, definida por $f(X)=X+X$ e $\mathrm{X}=\left[\mathrm{x}_{1}, \mathrm{x}_{2}\right] \subset \mathrm{D}$, um intervalo de valores reais pertencente ao seu domínio. Se $\mathrm{X}=[2$, 7], qual a sua imagem através da função f? Explique como chegou a essa conclusão. $\mathrm{O}$ que pode concluir sobre a imagem de um intervalo real qualquer, se a função f passar a ser definida por $\mathrm{f}(\mathrm{X})=\mathrm{X}^{2}$ ou por $\mathrm{f}(\mathrm{X})=\mathrm{e}^{\mathrm{x}}$ ?

Esta tarefa envolve os alunos em questões de natureza exploratória que servem de base à introdução de conceitos e de regras relativas à aritmética intervalar, ainda desconhecidas dos alunos. A primeira questão pretende levar os alunos a deduzirem essas mesmas regras e a justificá-las. Torna-se necessário a formulação, teste, refinamento e justificação de conjeturas a partir da exploração de casos particulares de operações elementares conhecidas (adição, subtração, multiplicação e divisão) utilizando intervalos de números reais. A segunda questão tem características semelhantes à anterior e pretende alargar o âmbito da aritmética intervalar às funções. Para resolvê-la é necessário recorrer a conhecimentos anteriores de funções e suas propriedades. A representação gráfica, se usada, pode facilitar a sua resolução. 


\section{Resolução de Gonçalo}

$\mathrm{O}$ aluno começa a exploração da tarefa procurando regularidades nos exemplos que são fornecidos no enunciado. Através da observação, Gonçalo formula uma conjetura para a adição de intervalos utilizando a linguagem natural: "Chegamos a essa conclusão efetuando a soma dos extremos inferiores e dos extremos superiores, partindo dos exemplos apresentados" (R). Depois explica o significado que construiu para o intervalo resultante da soma de intervalos:

Antes de comecarmos a tarefa eu nunca tinha visto a soma de intervalos e fiquei mesmo sem perceber do que é que se tratava. Mas depois percebi que considerando $\left[a_{1}, a_{2}\right]+\left[b_{1}, b_{2}\right]$ $=\left[c_{1}, c_{2}\right]$, tínhamos que qualquer valor compreendido entre $a_{1}$ e $a_{2}$, somado com qualquer valor entre $b_{1}$ e $b_{2}$, estaria compreendido no intervalo $c$. (E)

Para a subtração, o aluno formula uma conjetura por analogia com a regra da adição, mas modifica-a tendo em conta as propriedades dos números e das operações: "Para a subtração [...] apenas é aceite se transformarmos a subtração numa soma, isto é, $a-b=a+(-b)$. Trocaríamos $b_{1}$ e $b_{2}$ de extremos e assim já se podia aplicar a soma de extremo [com] extremo" (R). A compreensão do conceito de intervalo é fundamental na formulação das suas conjeturas para a multiplicação e divisão:

Basicamente era tentar encontrar o extremo minimo, era encontrar a menor multiplicação entre os dois intervalos, a menor de todas as combinações possiveis, e a maior. E uma maneira fácil de fazer isso era fazer todas as multiplicações dos extremos destes dois porque iam conter o maior e o menor quer no caso da multiplicação, quer da divisão. (E)

Gonçalo recorre à experimentação de alguns casos para validar as conjeturas formuladas: "Verificamos que, de facto, todas as regras funcionam em todos os intervalos reais após efetuar a experiência em diferentes intervalos. Tendo em conta que funcionou para os intervalos experimentados, aceitamos como verdadeira para todos”. (E)

$\mathrm{Na}$ questão seguinte, Gonçalo aplica diretamente a regra da adição deduzida na questão anterior: "Substituimos diretamente o 2 e o 7 e ficámos com uma soma de intervalos e já sabiamos como fazer" (E). Desta vez o aluno verifica o resultado através de um gráfico:

Concluimos que a imagem através da função é o intervalo $[4,14]$ [...]. Esta conclusão é corroborada pois a imagem da função (ver gráfico) vai ser o resultado da soma algébrica do intervalo [2, 7$]$.

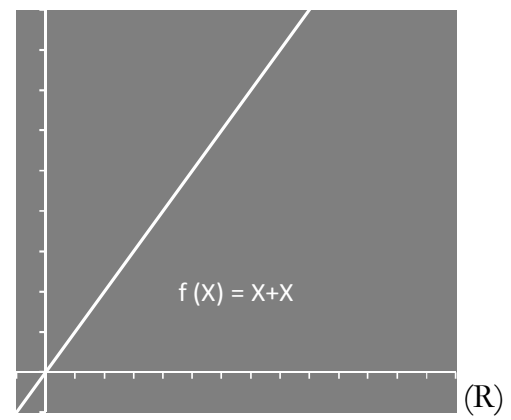


No caso da função dada por $f(X)=X^{2}$, Gonçalo começa por representar graficamente a função quadrática para procurar regularidades, com vista à formulação de uma conjetura sobre a imagem de um intervalo através desta função e conclui:

Primariamente analisamos o gráfico da função e concluimos que a imagem de um intervalo $X=[a, b]$ aleatório vai dar um intervalo de imagens e este vai depender do valor das coordenadas. Por exemplo, se uma era positiva, se era negativa, se o módulo de uma era maior que outra... Não podiamos generalizar apenas numa expressão o resultado pretendido. Por isso dividimos a função nos vários tipos de intervalos possiveis e obtivemos as várias opcões [...]. (E)

$$
\begin{aligned}
& \text { Se } a<0, b<0, f([a, b])=\left[b^{2}, a^{2}\right] \\
& \text { Ex: }[a, b]=[-4,-2]=>f([-4,-2])=[4,16] \\
& {[\cdots]} \\
& \text { Se } a<0, b=0, f([a, b])=\left[0, a^{2}\right] \\
& \text { Ex: }[a, b]=[-2,0]=>f([0,2])=[0,4](\mathrm{R})
\end{aligned}
$$

Em relação à função $f(X)=e^{x}$, Gonçalo volta a basear-se na análise do gráfico para formular uma regra e utiliza os mesmos casos anteriores quando, desta vez, é possível generalizá-la numa expressão única, uma vez que a função é monótona. Em nenhum destes casos, o aluno tenta justificar as conjeturas formuladas.

Resolução de Luís

O aluno interpreta a informação disponível, procurando recordar-se de experiências anteriores semelhantes: "Como nunca tinha feito uma soma de intervalos, associei logo à soma de vetores porque era a única coisa que era parecido com a soma de coordenadas. De acordo com as soluções encontradas nos exemplos ilustrados, verificamos que estes obedecem ao mesmo critério da adição de vetores" (E). É com base na observação dos exemplos dados no enunciado e nos seus conhecimentos sobre as propriedades dos vetores que Luís formula uma primeira conjetura para a soma de intervalos: "Sendo o vetor $\overrightarrow{\mathrm{U}}\left(u_{1}, u_{2}\right)$ e o vetor $\overrightarrow{\mathrm{V}}\left(v_{1}, v_{2}\right)$, a soma destes vetores é feita de acordo com o seguinte modo: $\overrightarrow{\mathrm{U}}+\overrightarrow{\mathrm{V}}=\left(u_{1}+v_{1}, u_{2}+v_{2}\right)$ '” (R). $\mathrm{O}$ aluno considera que a conjetura é válida para todos os valores reais e não sente a necessidade de a testar ou justificar, provavelmente porque está a aplicar um resultado já conhecido (a regra da adição de vetores).

Quando Luís tenta formular conjeturas para outras operações, encontra algumas dificuldades porque o resultado da aplicação das regras dos vetores não se ajusta ao seu conceito de intervalo: 
A subtração não [apresentou dificuldades] porque coincidia com a adição. Mas já a multiplicação e a divisão constituiam problemas. A multiplicação de vetores podia-se fazer pelo produto externo ou o produto escalar. [No entanto] o resultado do produto escalar é um número e [...] um intervalo é sempre representado por dois números, ou seja, o limite inferior e o limite superior. O produto externo... Também tem dois números, é verdade. Mas depois? [...] Já não sei, não me lembro. Mas depois como era intervalo tinha que colocar os outros números no meio, ou entre o limite inferior e superior e assim já não dá. (E)

O aluno abandona a estratégia inicial e, através da observação dos exemplos, identifica o padrão que está subjacente à construção dos intervalos. Formula uma nova conjetura para a adição de intervalos, generalizando-a, de imediato, escrevendo a regra em notação simbólica: " $\forall_{X, Y} \in \mathfrak{R}, X+Y=\left[x_{1}, x_{2}\right]+\left[y_{1}, y_{2}\right]=\left[x_{1}+y_{1}, x_{2}+y_{2}\right]$ ” (R).

Para a subtração, Luís formula uma conjetura com base em propriedades matemáticas dos números e das operações, e utiliza raciocínio dedutivo para obter uma regra para a subtração, através de manipulação algébrica:

$$
\begin{aligned}
& X=\left[x_{1}, x_{2}\right] \quad Y=\left[y_{1}, y_{2}\right] \\
& \begin{array}{l}
X-Y=X+(-Y)=\left[x_{1}, x_{2}\right]+\left(-\left[y_{1}, y_{2}\right]\right)=\left[x_{1}, x_{2}\right]+\left(\left[-y_{2},-y_{1}\right]\right)= \\
\quad=\left[x_{1}-y_{2}, x_{2}-y_{1}\right] .(\mathrm{R})
\end{array}
\end{aligned}
$$

O aluno não sente a necessidade de verificar nem de justificar a validade da regra, possivelmente porque a obteve através de um processo dedutivo com base em propriedades matemáticas. Luís formula, também, uma conjetura para a multiplicação de intervalos, por analogia com a regra da adição: "Para a multiplicação utilizamos o mesmo sistema que na adição. Multiplicamos os limites inferiores e os superiores dos dois intervalos: $\left[x_{1}, x_{2}\right] \times\left[y_{1}, y_{2}\right]=\left[x_{1} \times y_{1}, x_{2} \times y_{2}\right]$ " (R). Só quando questionado é que identifica algumas limitações da regra e utiliza o seu conceito de intervalo para refinar a conjetura: "Esta multiplicação só funciona para" $\mathfrak{R}_{0}^{+}(\mathrm{E})$. Para generalizar as regras propostas, o aluno utiliza a notação simbólica e constrói expressões algébricas que as formalizam, incluindo o uso correto de quantificadores, como mostra o exemplo:

$$
\forall_{Y} \in \mathcal{R} \backslash\{O\}, \mathrm{X} / \mathrm{Y}=\frac{\left[\mathrm{x}_{1}, \mathrm{x}_{2}\right]}{\left[\mathrm{y}_{1}, \mathrm{y}_{2}\right]}=\left[\frac{\mathrm{x}_{1}}{\mathrm{y}_{2}}, \frac{\mathrm{x}_{2}}{\mathrm{y}_{1}}\right] .
$$

Luís explica como interpreta a questão seguinte, tendo por base os seus conhecimentos sobre funções: 
Tendo em conta a noção de imagem que aprendemos anteriormente sabemos que se tem uma função y igual ao $f(x)$. [...] Se eu tenho um valor de $x$, eu tenho um valor de y que vai corresponder à imagem. Então eu considerei $[. .$.$] que dentro do intervalo \left[x_{1}, x_{2}\right]$, independentemente dos valores de $x_{1}$ e $x_{2}$, eu teria uma imagem para o intervalo $\left[x_{1}, x_{2}\right]$ que era substituir os valores de $x_{1}$ e $x_{2}$. (E)

No entanto, o aluno aplica diretamente a regra da adição deduzida na questão anterior: " $f\left(\left[x_{1}, x_{2}\right]\right)=\left[x_{1}, x_{2}\right]+\left[x_{1}, x_{2}\right]=\left[x_{1}+x_{1}, x_{2}+x_{2}\right][\ldots]$. Assim, $f([2,7])=[2,7]+[2,7]=[4,14] ”(\mathrm{R})$.

O aluno volta a aplicar as regras deduzidas anteriormente, neste caso a da multiplicação, no estudo da função $f(X)=X^{2}$. Só quando questionado é que Luís mostra reserva em relação à conjetura formulada: "Mas acho que ainda não é certo, não tenho conhecimentos para... Dados para defender isso. [...] de acordo com a multiplicação, multiplicar duas vezes o $X$ ” (E). Perante estas dúvidas, o aluno formula uma nova conjetura e coloca a questão: "Porque é que não poderia faz̧er o limite inferior ao quadrado e o limite superior ao quadrado?" (E). Nesta altura, o aluno testa as conjeturas com base na experimentação de casos e conclui que não são válidas: "Ao experimentar casos não dava o mesmo resultado de uma maneira e de outra" (E). No entanto, o aluno não identifica os motivos que estão na base da refutação e dá por terminada a exploração da tarefa, que fica incompleta: "Não consegui organizar as ideias para chegar lá...” (E).

\section{Representações}

Os alunos começam por utilizar a linguagem natural para descrever os seus raciocínios e justificar o modo de formação das regras das operações com intervalos. Mostram facilidade na conversão da linguagem natural para a algébrica, quando são solicitados a generalizar as regras, e também no uso de tratamentos dentro do sistema de representação algébrico, quando simplificam as expressões durante a sua dedução.

No entanto, a utilização de métodos algébricos de representação nem sempre é adequada para detectar conflitos e erros nas soluções obtidas. Como Luís não usa outro tipo de representação que permita verificar os resultados, as respostas que obtém com base na representação algébrica nem sempre estão corretas. Pelo seu lado, Gonçalo relaciona as representações algébricas e gráficas das funções e tira partido dessa relação para facilitar a identificação de propriedades das funções que são fundamentais para obter e confirmar resultados.

\section{Processos de raciocínio}

As estratégias iniciais dos dois alunos têm um caráter eminentemente indutivo, pois partem da observação de exemplos ou utilizam analogias para 
formularem as suas primeiras conjeturas. Luís tem tendência para generalizar as conjeturas, de forma imediata, sem proceder à sua validação. Deste modo, as conjeturas que formula nem sempre são corretas. Só quando questionado é que testa as conjeturas recorrendo a alguns exemplos. Já Gonçalo, pelo contrário, tem sempre a preocupação de testar as suas conjeturas recorrendo à experimentação de alguns casos ou comparando os resultados obtidos a partir de diferentes estratégias. Os dois alunos só justificam conjeturas quando utilizam processos de raciocínio dedutivo para as formular, tendo em conta conceitos e propriedades matemáticas suas conhecidas, como a subtração de intervalos de valores reais.

\section{Significação}

A exploração da tarefa proposta permitiu aos alunos desenvolver a compreensão do conceito de intervalo e das regras da aritmética intervalar fazendo conexões com outros tópicos matemáticos, em particular com o conhecimento que já tinham sobre propriedades dos números e das funções. Gonçalo utiliza o conceito de intervalo para formular conjeturas, por exemplo, sobre as regras para a multiplicação ou divisão de intervalos. Além disso, o uso da representação gráfica e de propriedades de funções parece ter ajudado o aluno a construir significado para a imagem de um intervalo através de funções, com vista à formulação (e posterior validação) de conjeturas. Pelo seu lado, Luís tentou dar significado à soma de intervalos relacionando-a com os conhecimentos prévios da soma de vetores. No entanto, utiliza a sua compreensão do conceito de intervalo para identificar erros e questionar a estratégia inicial. Para ambos os alunos, é a utilização de raciocínio dedutivo para encontrar a regra da subtração que permite simultaneamente confirmar as suas ideias ou intuições iniciais e perceber porque são verdadeiras.

\section{Conclusão}

O domínio da linguagem algébrica por parte dos alunos do $9^{\circ}$ ano é ainda insuficiente para resolverem de forma expedita os problemas propostos. Duarte só generaliza a sua conjetura quando isso lhe é sugerido e sente necessidade de concretizar a expressão algébrica que obtém, experimentando um caso particular. Mostra-se capaz de realizar tratamentos, como a simplificação de expressões algébricas, mas revela dificuldades na conversão da linguagem algébrica para a natural, o que limita seriamente o seu raciocínio, que precisaria de se basear numa variedade de registros de representação e na sua coordenação (DUVAL, 2004). Maria, pelo seu lado, mostra também algumas dificuldades na conversão da linguagem natural para a algébrica, mas aparenta ter desenvolvido estruturas de representação muito mais consistentes. 
Gonçalo e Luís utilizam a representação algébrica com destreza e revelam facilidade na conversão entre diferentes registros (linguagem natural, linguagem algébrica e representação gráfica). Usam sobretudo a linguagem natural para descrever e justificar os seus raciocínios. No entanto, quando solicitados a generalizar as suas conjeturas, recorrem à linguagem algébrica e mostram facilidade tanto na realização de tratamentos, quando simplificam expressões matemáticas, como na conversão da linguagem natural para a algébrica. Gonçalo mostra-se mesmo capaz de utilizar diferentes representações e tira partido da relação entre elas para obter resultados corretos, apoiando a ideia do valor das representações matemáticas para a comunicação do raciocínio (NCTM, 2007). Os alunos com maior capacidade de realizar conversões são também os que evidenciam maior capacidade de realizar raciocínios dedutivos.

Inicialmente, os raciocínios dos alunos, tanto do $9^{\circ}$ ano como do Ensino Superior, tendem a desenvolver-se do particular para o geral. Os alunos usam essencialmente processos indutivos, como observação de casos particulares, analogia e generalização para formularem as suas primeiras conjeturas. De um modo geral, não sentem necessidade de justificar as conjeturas, tal como, de resto, se tem verificado em trabalhos anteriores (PONTE, 2007). Assim, Luís tem tendência para generalizar de imediato as suas conjeturas e não sente a necessidade de as testar ou justificar e, tal como Duarte, quando é solicitado a fazê-lo, experimenta casos particulares como processo de validação (como indicado por KIERAN, 2007). Duarte mostra não compreender o papel da linguagem algébrica na justificação e, deste modo, não consegue raciocinar dedutivamente. Maria tira partido do seu domínio da linguagem algébrica para justificar a sua conjetura. Estas justificações constituem um aspeto do raciocínio dedutivo, sendo dadas em linguagem natural, com recurso à linguagem algébrica, ou seja, ainda que sem muita formalização, a aluna consegue encadear asserções de forma lógica e justificar esse encadeamento. Gonçalo é o único aluno que revela preocupação em testar as conjeturas e realiza-o de forma autônoma recorrendo à experimentação de alguns casos ou comparando os resultados obtidos a partir de diferentes estratégias, sobretudo gráficas. Tanto Gonçalo como Luís são capazes de utilizar raciocínio dedutivo para justificar conjeturas. Também, como seria de esperar neste nível de ensino, a sua justificação é apoiada em conhecimento anterior de procedimentos, propriedades e conceitos matemáticos.

Os níveis de significação variam muito de aluno para aluno. Assim, Maria associa a expressão simplificada ao conceito de múltiplo, evidenciando compreender o que está a ser demonstrado. Duarte, pelo seu lado, realiza procedimentos mas não dá significado à expressão algébrica que obtém. Não estabelece relação entre a expressão algébrica simplificada e os conceitos que já conhece e tem dificuldade em relacionar expressões numéricas e algébricas. No caso 
de Gonçalo e Luís, a exploração da tarefa proposta permite-lhes desenvolver a compreensão do conceito de intervalo e das regras da aritmética intervalar fazendo conexões com tópicos matemáticos como propriedades dos números e das funções. Luís tenta dar significado à soma de intervalos relacionando-a com os conhecimentos prévios da soma de vetores e usa a sua compreensão do conceito de intervalo para identificar erros e questionar a estratégia inicial. É a utilização de raciocínio dedutivo para encontrar a regra da subtração que permite a ambos os alunos confirmar as suas ideias iniciais e perceber porque são verdadeiras.

O modelo de análise que usamos (Figura 1) revelou-se um instrumento muito útil para estudar os processos de raciocínio dos alunos, articulando o raciocínio com as representações e a significação. Os quatro processos de raciocínio (formulação de questões, formulação de conjeturas, teste e justificação) foram identificados no trabalho dos alunos. A distinção entre conjeturas específicas e gerais também se revelou pertinente no caso dos alunos do ensino superior, correspondendo a diversos tipos de generalização (raciocínio indutivo). Este modelo de análise, certamente poderá ser ainda aperfeiçoado, mas parece útil tanto investigação como na formação de professores.

O desenvolvimento da capacidade de raciocinar matematicamente é um dos aspetos salientes do novo programa de Matemática do ensino básico (ME, 2007). Será interessante verificar no futuro se a generalização do novo programa irá promover este desenvolvimento, habilitando os alunos a usar tanto o raciocínio indutivo como o dedutivo e reforçando processos de raciocínio como a formulação de conjeturas e a justificação. Será também importante verificar se os alunos serão capazes de recorrer a várias representações, para que as conversões entre elas se tornem mais simples, desenvolvendo uma maior compreensão dos objetos e conceitos matemáticos, e uma maior riqueza de significações. Para que isso possa acontecer, não basta que exista um novo programa de Matemática, valorizando o raciocínio. Será necessário que os professores conheçam os processos de raciocínio dos seus alunos e reflitam sobre eles. Se esta análise revelar lacunas, mesmo de aqueles que mostram bom desempenho, será necessário colmatá-las para que os alunos sejam mais críticos e desenvolvam a Matemática com compreensão. Tudo isto requer, certamente, um trabalho específico no âmbito do desenvolvimento curricular e das práticas profissionais na sala de aula.

\section{Referências}

ALISEDA, A. Mathematical reasoning vs. abductive reasoning: a structural approach. Synthese, n. 134, p. 25-44, 2003.

ARZARELLO, F.; BAZZINI, L.; CHIAPINNI, G. A model for analysing processes of thinking. In: SUTHERLAND, R.; ROJANO, T.; BELL, A.; LINS, R. Perspectives on school algebra. Dordrecht: Kluwer, 2002. p. 61-81. 
BOAVIDA, A. M.; PAIVA, A. L.; CEBOLA, G.; VALE, I.; PIMENTEL, T. A experiência matemática no ensino básico. Lisboa: DGIDC, 2008.

BOGDAN, R.; BIKLEN, S. Investigação qualitativa em educação: uma introdução à teoria e aos métodos. Porto: Porto Editora, 1994.

CARREIRA, S. Conexões matemáticas - ligar o que se foi desligando. Educação e Matemática, Lisboa, n. 110, p. 13-18, 2010.

DUVAL, R. Semiosis y pensamiento humano. Colombia: Merlín, 2004.

A cognitive analysis of problems of comprehension in a learning of mathematics.

Educational Studies in Mathematics, n. 61, p. 103-131, 2006. DOI: 10.1007/s10649-006$0400-z$

GOLDIN, G. Perspectives on representation in mathematical learning and problem solving. In: ENGLISH, L. D. Handbook of international research in mathematics education. Nova York: Taylor \& Francis, 2008. p. 176-201.

GREENO, J.; HALL, R. Practicing representation. Phi Delta Kappan, n. 78, p. 361-367, 1997.

HANNA, G. Proof and its classroom role: a survey. In: ENCONTRO DE INVESTIGAÇÃO EM EDUCAÇÃO MATEMÁTICA - EIEM, 9., 2000, Fundão. Actas... Fundão: SPCESEM, 2000. p. 75-104.

HOWSON, A. G. Meaning and school mathematics. In: KILPATRICK, J.; HOYLES C.; SKOVSMOSE, O. (Eds.). Meaning in mathematics education. Dordrecht: Kluwer, 2005. p. 17-38.

KIERAN, C. Learning and teaching of algebra at the middle school through college levels. In: LESTER, F. (Ed.). Second handbook of research on mathematics teaching and learning. Reston: NCTM, 2007. p. 707-762.

MATA-PEREIRA, J.; PONTE, J. P. Raciocínio matemático em contexto algébrico: uma análise com alunos do 9. ${ }^{\circ}$ ano. In: ENCONTRO DE INVESTIGAÇÃO EM EDUCAÇÃO MATEMÁTICA, 2011, Lisboa. Actas... Lisboa: SPIEM, 2011. p. 347-364. Disponível em: $<$ http://spiem.pt/DOCS/ATAS_ENCONTROS/2011/2011_17_JMPereira.pdf>. Acesso em: 21 nov. 2012.

ME. Programa de matemática: plano de organização do ensino-aprendizagem - ensino básico $3^{\circ}$ ciclo. Lisboa: DES-ME, 1992.

Programa de matemática do ensino básico. DGIDC-ME, 2007. Disponível em: <http://sitio.dgidc.min-edu.pt/matematica/Documents/ProgramaMatematica.pdf $>$. Acesso em: 16 jan. 2008.

NCTM. Princípios e normas para a Matemática escolar. Lisboa: APM, 2007.

Focus in high school mathematics: reasoning and sense making. Reston: NCTM, 2009.

OLIVEIRA, P. A investigação do professor, do matemático e do aluno: uma discussão epistemológica. 2002. 285 f. Dissertação (Mestrado em Didáctica da Matemática) Universidade de Lisboa, Lisboa, 2002. 
O raciocínio matemático à luz de uma epistemologia. Educação e Matemática, Lisboa, n. 100, p 3-9, 2008.

PÓLYA, G. Mathematics and plausible reasoning: induction and analogy in mathematics. New Jersey: Princeton University Press, 1954.

PONTE, J. P. Investigations and explorations in the mathematics classroom. ZDM Mathematics Education, v. 39, n. 5-6, p. 419-430, 2007.

PONTE, J. P.; BROCARDO, J.; OLIVEIRA, H. Investigações matemáticas na sala de aula. Belo Horizonte: Autêntica, 2003.

PONTE, J. P.; SOUSA, H. Uma oportunidade de mudança na matemática no ensino básico. In: APM. O professor e o programa de Matemática do Ensino Básico. Lisboa: APM, 2010. p. 11- 41.

RUSSEL, S. Mathematical reasoning in the elementary grades. In: STIFF, L. V.; CURCIO, F. R. (Eds.). Developing mathematical reasoning in grades K-12. Reston: NCTM, 1999. p. 1-12.

STAKE, R. A arte da investigação com estudos de caso. Lisboa: Fundação Calouste Gulbenkian, 2009.

VERNAUD, G. A comprehensive theory of representation for mathematics education. Journal of Mathematical Behavior, v. 2, n. 17, p. 167-181, 1998. DOI: 10.1016/S03640213(99)80057-3

Recebido em 15/01/2012

Aceito em 20/04/2012 